\title{
ESCUELA COMPREHENSIVA O ESCUELA SELECTIVA
}

\section{COMPREHENSIVE SCHOOL OR SELECTIVE SCHOOL}

Marcos A. Díaz: Columnista.

marcos-diaz@gmail.com

\section{CURRÍCULUM VITAE}

Profesor de Enseñanza Secundaria en Oviedo, columnista de La Nueva España, Diario de América y Asturias Liberal, y blogger liberal.

\section{RESUMEN}

La escuela comprehensiva reúne a chicos con distintas capacidades, talentos y trayectorias y los escolariza en el mismo aula. El gremio docente, en general, prefiere la escuela comprehensiva a la selectiva. Ésta es considerada segregadora y germen de desigualdades y rencor social.

\section{PALABRAS CLAVE}

Escuela - Capacidades - Desigualdad 
The comprehensive school brings together children with diverse abilities, talents and backgrounds and schooling in the same classroom. The teachers' union generally preferred to selective comprehensive school. This is considered segregating germ and social inequalities and resentment.

\section{KEY WORDS}

School - Abilities - Inequality

\section{TEXTO:}

Uno de los grandes debates seculares sobre la organización escolar es la dualidad entre escuela comprehensiva y escuela selectiva.

La primera reúne a chicos con distintas capacidades, talentos y trayectorias y los escolariza en el mismo aula. Conviven pupitre con pupitre mil y una personalidades hermosas e irrepetibles: la cerebrito de las mates antipática y repipi pero con buen corazón, el líder amigo de todos, el chaval que no entiende los textos que lee, el otro que a duras penas ha roto a leer... Éste, a su vez, al lado del piloso repetidor, dos años mayor que el resto y la chica inmigrante por la que aquél suspira en vano. Todos con el deportista, la alumna del conservatorio, el que cuenta por los dedos y el pandillero juvenil. El creativo con el sistemático, el pasota con el responsable, el maduro con el cándido... Dado que no todos somos iguales y que es en la pluralidad precisamente donde reside la riqueza, el aula es un microcosmos reflejo del mundo real y un perfecto laboratorio de socialización. 
Sin embargo, debemos ser tan justos con los inconvenientes de la escuela comprehensiva como con sus ventajas. El profesor de Matemática o el de Historia debe ponderar las distintas capacidades de sus alumnos, de forma que ninguno quede rezagado. Distintos ritmos de aprendizaje suelen suponer en la práctica, descender al más lento de ellos pues el nivelado nunca es por elevación sino por rebajamiento. La triste consecuencia es que muchas potencialidades queden sin optimizar y se desperdicien por mal explotados grandes talentos.

Un ejemplo de esta filosofía educativa es el sistema español. El gremio docente, en general, prefiere la escuela comprehensiva a la selectiva. Ésta es considerada segregadora y germen de desigualdades y rencor social. No obstante, el resultado es paradójico, porque no aplicar la selección de alumnado es precisamente lo que genera más desigualdad e injusticia social. Cuando un joven brillante de familia pobre sólo cuenta con la escuela comprehensiva pública como único ascensor social, el privilegio de la educación selectiva y la excelencia se convierte en un lujo de ricos. ¿Es algo inevitable? Ciertamente no, ya que en Inglaterra hay un sistema llamado Grammar Schools, bastante eficaz en este punto.

David W. es inglés y estudiante de la Universidad de Liverpool. Tiene 20 años, procede de una familia humilde y, a día de hoy, es auxiliar de conversación del Instituto donde trabajo. Parte de su formación lingüística consiste en pasar este año en España como lector de inglés. Su carácter agradable y accesible resulta tan alejado de los estereotipos que se cuentan de sus compatriotas como poco común a su edad. A pesar de su juventud, se nota enseguida que es un tipo espabilado; las ideas claras, ojos y oídos alerta y el ingenio despierto. Con apenas dos años de español a sus espaldas, ya se maneja en nuestro idioma con una destreza impropia del anglosajón y en la que mezcla buenas dosis de humor y perspicacia. 
David recibió su educación secundaria, de la que aún guarda un vívido recuerdo, en el sistema público de su país. Él, como tantos otros chicos británicos, ha crecido en la atmósfera de la escuela selectiva. Al cumplir los 11 años, el Estado les somete a un examen estándar de lengua y matemáticas para comprobar lo que han aprendido durante la primaria. Este test, llamado eleven plus por la edad de sus examinandos, supone la primera cita del niño inglés con el concepto de responsabilidad y la idea de rendir cuentas de los propios actos. Con cierta contención británica, David me explica cómo su madre exigía el máximo esfuerzo de él y sus dos hermanos para cumplir en el 11+ y la importancia que esta cita tenía desde la más tierna infancia para la familia. De ella dependía poder entrar en una Grammar School o conformarse con una escuela comprehensiva. Lo cierto es que aunque muchas voces se elevan en su país y en el nuestro contra la idea de examinar a los niños a tan tierna edad, David no parece muy traumatizado por tan espantoso trance.

Una Grammar school recibe dotación presupuestaria adicional a la de una escuela comprehensiva y sus criterios de selección de alumnos son estrictamente los de mérito y capacidad reflejados en el test $11+$. Sus alumnos se distribuyen en cada curso en diferentes grupos siguiendo el orden decreciente de sus medias académicas. De acuerdo con esta filosofía, quien obtiene mejores notas puede progresar al año siguiente a una clase de mejor nivel; merito y capacidad para entrar en la institución, mérito y capacidad para promocionar en ella: si estudia, ascenderá a una clase mejor para sus intereses, con un ritmo de aprendizaje ajustado a sus capacidades y la competencia con compañeros del mismo perfil que estimulará su rendimiento.

El legislador británico quiso defender con esta doble vía de escolarización el derecho del pobre a la excelencia educativa cuando demuestra talento. Segregar los itinerarios educativos dentro de la educación pública es una garantía de cohesión social y no una vía de división como arguyen sus detractores. 
El debate entre escuela comprehensiva y escuela selectiva sigue tan abierto en el Reino Unido como en España y otros muchos países. Toda su compleja realidad se resume en una disyuntiva. ¿Mediocridad a través del igualitarismo u oportunidades mediante la excelencia? 